\title{
Pilot-Scale Investigation of Forward/Reverse Osmosis Hybrid System for Seawater Desalination Using Impaired Water from Steel Industry
}

\author{
Hanaa M. Ali, Hanaa Gadallah, Sahar S. Ali, Rania Sabry, and A. G. Gadallah \\ Chemical Engineering and Pilot-Plant Department, National Research Center, Cairo 12622, Egypt \\ Correspondence should be addressed to Hanaa M. Ali; hanaa_aly@hotmail.com
}

Received 28 October 2015; Accepted 16 February 2016

Academic Editor: Jean-Pierre Corriou

Copyright (c) 2016 Hanaa M. Ali et al. This is an open access article distributed under the Creative Commons Attribution License, which permits unrestricted use, distribution, and reproduction in any medium, provided the original work is properly cited.

\begin{abstract}
This paper was focused on the investigation of a forward osmosis- (FO-) reverse osmosis (RO) hybrid process to cotreat seawater and impaired water from steel industry. By using this hybrid process, seawater can be diluted before desalination, hence reducing the energy cost of desalination, and simultaneously contaminants present in the impaired water are prevented from migrating into the product water through the FO and RO membranes. The main objective of this work was to investigate on pilot-scale system the performance of the combined FO pretreatment and RO desalination hybrid system and specifically its effects on membrane fouling and overall solute rejection. Firstly, optimization of the pilot-scale FO process to obtain the most suitable and stable operating conditions for practical application was investigated. Secondly, pilot-scale RO process performance as a posttreatment to FO process was evaluated in terms of water flux and rejection. The results indicated that the salinity of seawater reduced from 35000 to $13000 \mathrm{mg} / \mathrm{L}$ after 3 hrs using FO system, while after 6 hrs it approached $10000 \mathrm{mg} / \mathrm{L}$. Finally, FO/RO system was tested on continuous operation for $15 \mathrm{hrs}$ and it was demonstrated that no pollutant was detected neither in draw solution nor in RO permeate after the end of operating time.
\end{abstract}

\section{Introduction}

With the limitation of fresh water resources, the use of alternative sources like desalination or water reuse is highly studied and developed. RO desalination is a pressure-driven membrane process in which water from a saline feed solution is pushed through a membrane at a hydraulic pressure that exceeds the osmotic pressure of the saline solution. Because of the differences in solubility and diffusivity between water and salt ions, most salt ions are retained by the semipermeable membrane. Although RO is currently the most energy efficient desalination technology, it still requires a great deal of energy to create the high pressures necessary to desalinate seawater [1]. In this context, FO is now an emerging separation technology that promises low energy consumption and low fouling issues in comparison to $\mathrm{RO}$ process for desalination. FO is a spontaneous process in which water is transported through a semipermeable membrane due to a difference in chemical potential between two solutions.
Water will naturally diffuse through the membrane from the freshwater side to dilute the higher saline solution [2]. The combination of FO and RO promises a high value complementary process to bolt to seawater RO plants, in which FO can be used to draw fresh water from tertiary wastewater effluent using seawater, and then using RO to desalt the diluted seawater could allow existing desalination plants to reduce energy demand or increase water recovery [3]. Recently, many research articles were focused on studying of FO and FO hybrid systems in different applications. Kim et al. [4] proposed a hybrid $\mathrm{FO} /$ crystallization/RO process for seawater desalination, and the theoretical analysis of the process was conducted. When the FO unit is considered as the main desalination unit, the crystallization and RO units can be regarded as a draw solute recovery process. Phuntsho et al. [5] studied the use of nanofiltration as an integrated process to fertilizer drawn forward osmosis desalination, either as a pretreatment or posttreatment, to reduce the nutrient concentrations in the final product water and thereby allow 
direct use of the product water for fertigation without further dilution. Altaee et al. [6] evaluated the performance of pressure retarded osmosis-reverse osmosis (PRO-RO) process for power generation and seawater desalination. The draw and feed solutions in the FO process were seawater and lowquality water, that is, wastewater effluent and brackish water. Xie et al. [7] elucidated the relationship between membrane properties and the rejection of trace organic contaminants in FO. Kong et al. [8] experimentally determined and mathematically modeled the rejection of haloacetic acids by FO and the coupled reverse draw solute permeation by using the solution-diffusion model for both the AL-FW (active layer facing the feed water) and the AL-DS (active layer facing the draw solution) orientations. Lutchmiah et al. [9] presented a review that attempted to define the steps still required for FO to reach full-scale potential in wastewater treatment and water reclamation by discussing current novelties, bottlenecks, and future perspectives of FO technology in the wastewater sector. They concluded that ineffective membranes and reverse solute leakage remain the main challenges hindering the growth of FO-wastewater applications. The use of hybrid systems, such as FO-MD, FORO, and FO-NF, can enhance $\mathrm{FO}$ and make it commercially feasible for wastewater recovery. Raval and Koradiya [10] studied direct fertigation with brackish water by FO system converting domestic RO module into FO membrane element.

An example of an operating plant in the desalination industry is Al Khaluf, a site $400 \mathrm{~km}$ south of Muscat, incorporating Modern Water's $100 \mathrm{~m}^{3}$ per day unit, which operates alongside a conventional SWRO system owned by the Public Authority for Electricity and Water. The FO part of the process operates at $35 \%$ recovery to dilute the draw solution before it is desalinated by high-pressure SWRO membranes to produce potable water with $120 \mathrm{mg} / \mathrm{L}$ TDS [11]. Another example is present at Korea Maritime University in Busan with $\mathrm{FO} / \mathrm{RO}$ pilot plant that produces 20 tons of fresh water per day. It showed that this hybrid process can save about 20 percent of energy compared to the existing RO process, consuming $4 \mathrm{kWh}$ to $10 \mathrm{kWh}$ to produce one ton of fresh water. It will allow the fresh water production cost to be lower than 0.65 Euros per ton [12].

The main objective of this work was to investigate on pilot-scale the performance of the combined forward osmosis pretreatment and reverse osmosis desalination hybrid system to cotreat seawater and impaired water from steel industry. In addition, the effect of impaired water on membrane fouling and overall solute rejection was demonstrated.

\section{Materials and Methods}

\subsection{Materials}

2.1.1. Feed and Draw Solutions. Ezz Steel is the Middle East's leading producer of high-quality long and flat steel for use in a wide range of end applications. Ezz Steel plant in Alexandria (Egypt) is located close to Mediterranean Sea; the treated wastewater from the factory is discharged directly into the

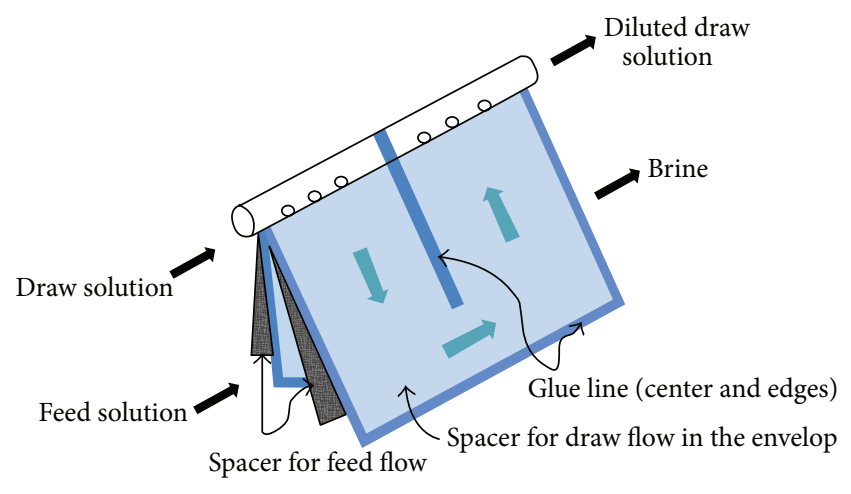

FIGURE 1: Schematic diagram of a spiral wound forward osmosis (FO) module showing the direction of water in the module.

seawater. Accordingly, the treated wastewater from this factory was selected to be used as feed solution (FS), while $\mathrm{NaCl}$ was used to prepare synthetic seawater as draw solution (DS).

\subsubsection{Membranes}

(1) FO Membrane. A spiral wound FO membrane module was used in this study. The spiral wound (SW) membrane module was 4040 FO-FS module made up of several flatsheet cellulose triacetate (CTA) with embedded polyester FO membranes (Hydration Technologies, Albany, OR). The number 4040 refers to the module diameter of $0.1016 \mathrm{~m}^{2}$ and the module length of $1.016 \mathrm{~m}^{2}$. The $4040 \mathrm{FO}-\mathrm{FS}$ membrane module has a usable area of $3.2 \mathrm{~m}^{2}$. The module was operated with the feed water against the active rejection layer passing through the membrane in the axial direction parallel to the permeate tube. The draw solution faces the porous support layer of the membrane and flows spirally inside the membrane; thus, it is diluted by the water extracted from the feed water. The diluted DS is collected in the permeate tube as illustrated in Figure 1. The SW FO element was loaded inside a tubular polyvinyl chloride (PVC) vessel.

(2) RO Membrane Module. The membrane element is Filmtec, spiral wound, type BW 30-40-40, TFC (polyamide composite), pore size $\sim 0.0001$ microns, and maximum pressure is 16 bar. The effective membrane area is $7.2 \mathrm{~m}^{2}$, the maximum permeate flow rate is $6 \mathrm{~m}^{3} /$ day, and salt rejection is $99.3 \%$.

2.2. Experimental Setup. The schematic diagram of the pilotscale of the FO-RO system is shown in Figure 2. It consisted of microfiltration (MF) to minimize the negative effects of the raw feed, the FO process to desalinate draw solution using the synthetic salt solution as DS and industrial wastewater as FS, and the RO process to reduce the salt in the final product. Each flow was controlled independently by a pump, and the draw and feed solutions in the FO process flowed in cocurrent mode in each channel on both sides of the membrane. Figure 3 shows the image of pilot-scale unit.

The water flux across the membrane in the FO process was measured by the change in the weight of the DS tank. The conductivity of the feed and draw solutions in the FO 


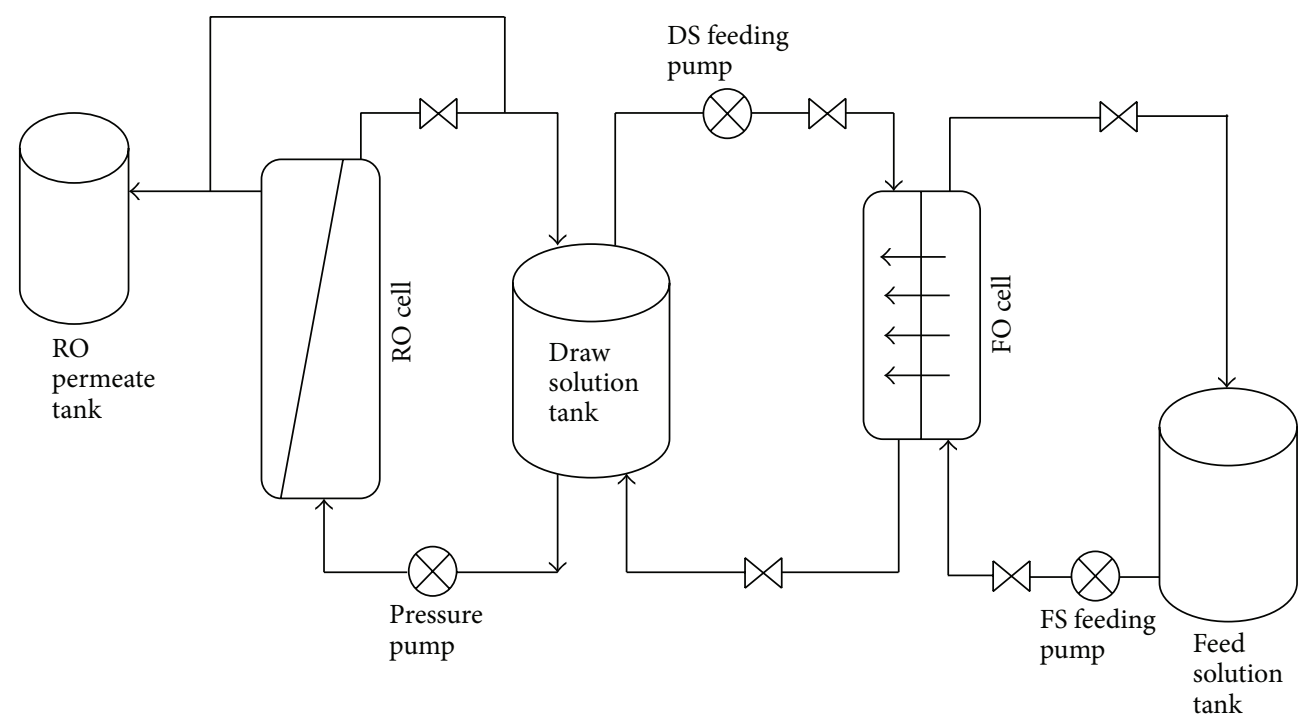

Figure 2: Schematic drawing of the FO/RO experimental setup.

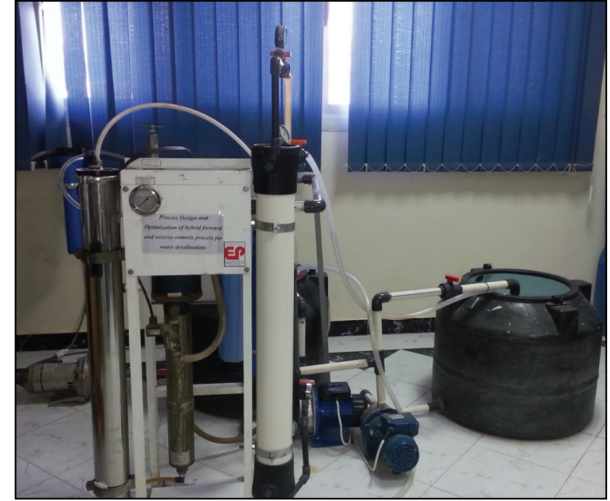

Figure 3: An image of the FO/RO pilot-scale unit.

process and the permeate flux in the $\mathrm{RO}$ process were also collected during the test. The experiments were conducted in a batch mode. Water flux was calculated using the following relationship:

$$
J w=\frac{\text { Change in DS weight }(\mathrm{L})}{\text { Effective membrane area }\left(\mathrm{m}^{2}\right) \times \text { Time }(\mathrm{h})} .
$$

The $\mathrm{RO}$ process was evaluated as a posttreatment for the FO process to achieve a suitable concentration in the final product water. The concentrated solution and the permeate water were recirculated and reused during the pilot-scale RO operation.

The permeate water flux $J w\left(\mathrm{Lm}^{-2} \mathrm{~h}^{-1}\right)$ was calculated by

$$
J w=\frac{\text { Volume of water collected }(\mathrm{L})}{\text { Membrane area }\left(\mathrm{m}^{2}\right) \times \text { Time }(\mathrm{h})} .
$$

Furthermore, the salt rejection of the pressure-driven $\mathrm{RO}$ membrane was calculated by measuring the total dissolved solid of the feed and permeates $(\mathrm{mS} / \mathrm{cm})$ :

$$
R(\%)=1-\frac{C_{\text {permeate }}}{C_{\text {feed }}} .
$$

\subsection{FO-RO Pilot Experimental Procedure}

2.3.1. Batch Experimental Plan. In the batch experiments, the application of $\mathrm{FO} / \mathrm{RO}$ hybrid system in industrial scale was investigated. Figure 4 shows the proposed plant for seawater desalination and Ezz Steel treated wastewater concentration. In the proposed plant, the first stage FO uses seawater as DS to extract water from Ezz Steel treated wastewater FS. The diluted seawater is then processed through an RO desalination system that provides high salt rejection and dissolved contaminants that may have escaped the FO treatment, hence achieving a multibarrier treatment system. Furthermore, a second FO stage can be installed between the RO concentrate stream and the concentrated FS from the first FO stage to extract additional water from the Ezz Steel wastewater stream, reducing its volume. Consequently, the concentrated Ezz Steel wastewater stream could be returned to a wastewater treatment plant for retreatment or used for beneficial purposes. So, the RO concentrate is diluted, thus reducing the environmental impacts associated with discharging RO brine back to the sea.

Accordingly, each step in the proposed system was tested separately; this includes the following.

(a) 1st Stage and 2nd Stage of FO Performance. Water flux, DS dilution, salt rejection, and transfer salt flux were measured with time. In addition, transfer of the major contaminants of Ezz Steel wastewater (COD, $\mathrm{Fe}, \mathrm{Zn}$, and $\mathrm{PO}_{4}$ ) across the $\mathrm{FO}$ membrane was tested. 


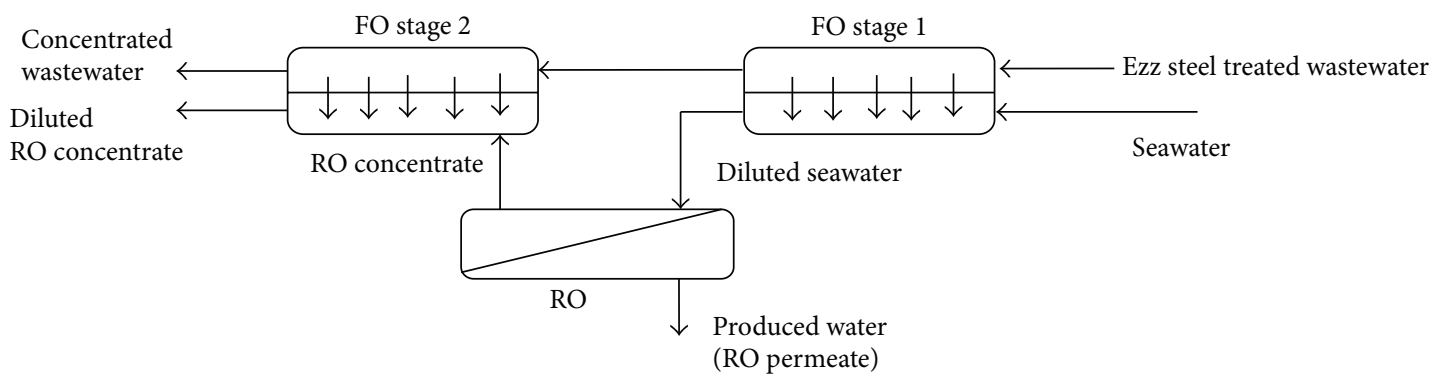

FIgURE 4: Proposed FO/RO plant for seawater desalination using Ezz Steel treated wastewater.

(b) RO Performance. The effect of applied pressure on performance of RO with diluted seawater from 1st stage of FO was tested. This includes measuring of RO permeate water flux, salt rejection, and overall water recovery.

2.3.2. Continuous Experimental Plan. The continuous operation of $\mathrm{FO} / \mathrm{RO}$ system was conducted to assess membrane fouling propensity, solute rejection, and any subsequent degradation in performance of the hybrid process and to investigate rejection of contaminants during the operation of the hybrid process. Diluted draw solution from the FO membrane cell returned to the RO feed tank and an RO permeate partial stream (equivalent to the flow rate of water through the FO membrane) were removed from the system. The amount decreased from the feed tank compensated by addition of distilled water.

2.4. Analysis and Measurements. Samples were collected throughout the course of each experiment. For all experiments of (synthetic or real) wastewater, $50 \mathrm{~mL}$ samples was collected for analysis from the feed and draw solutions. Analysis of inorganic ions $\mathrm{Fe}(\mathrm{III}), \mathrm{PO}_{4}(\mathrm{III})$, and $\mathrm{Zn}$ (II) at FS and DS for each experiment was determined using spectrophotometer HACH DR2800. Organic substances were determined as COD. TDS for each experiment was determined according to standard method (APHA, AWWA, and WEF 2005).

\section{Results and Discussions}

3.1. Batch Experiments Results. Based on the results of our previous bench scale investigation work [13], it was concluded that the performance of FO with treated wastewater as FS gives good results in seawater dilution. Here, the performance on pilot-scale was studied with real wastewater to test industrial implementation of the process.

3.1.1. 1st Stage of FO Process. Figure 5 shows the effect of permeation time on water flux and reverse solute flux for first stage of FO process. It is clear that high water flux value was observed in the beginning of the operation and then slightly decreased by time, where it is decreased from $8.44 \mathrm{~L} / \mathrm{m}^{2} \mathrm{hr}$ at $1 \mathrm{hr}$ to 6.61 at $6 \mathrm{hrs}$. For the transfer salt flux, nearly the same trend was observed, in which it reached $0.085 \mathrm{~mol} . / \mathrm{m}^{2} \mathrm{hr}$ at $2 \mathrm{hrs}$ and then decreased to 0.041 at $6 \mathrm{hrs}$.

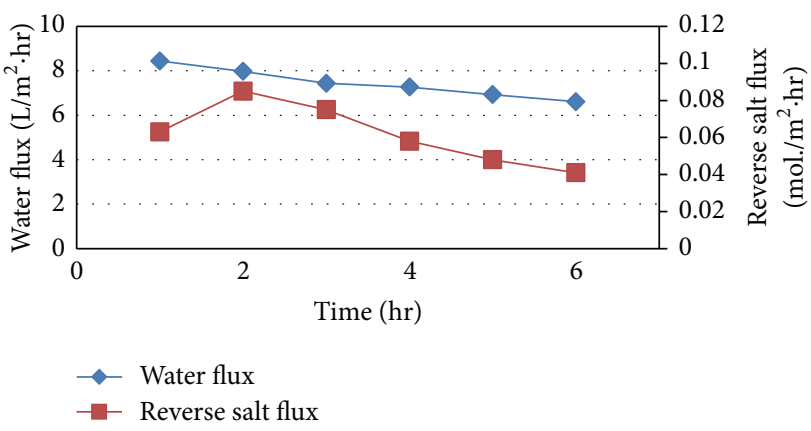

FIGURE 5: Water and reverse solute fluxes as a function of time (1st stage of FO-batch process).

The behavior of flux decline with time was illustrated by Zhao et al. [14], they demonstrated that coupled adverse effects of internal concentration polarization (ICP) and membrane fouling can reduce the osmotic water flux and increase mass transfer resistance as the feed water became more concentrated due to water permeation from FS to DS and reverse salt diffusion from DS to FS.

By comparing the results with bench scale results of our previous work, a better FO performance was observed in pilot experiments, in which the maximum flux in bench scale with the real wastewater was found to be $5.2 \mathrm{~L} / \mathrm{m}^{2} \mathrm{hr}$. This may be attributed to the enhancing of operating conditions in pilot experiments. Where based on recommendation of the FO module inventor, a slight pressure (40 psi) was applied on FS side; this may cause an increasing of water permeation rate from FS to DS. This result is in good agreement with Blandin et al. [15]; they studied assisted forward osmosis (AFO) that aims at pressurizing the feed solution of FO process to enhance water permeation through synergizing osmotic and hydraulic driving forces. They found that when 6 bar was applied on the feed side, the membrane water permeability was doubled.

The effect of operating time on dilution rate of DS was illustrated in Figure 6, which shows gradual increase in dilution percent by water permeation from FS to DS from about $50 \%$ at $1 \mathrm{hr}$ to $250 \%$ after $6 \mathrm{hrs}$. Figure 7 shows DS salinity and salt rejection as a function of FO permeation time; as expected from dilution effect, the TDS of DS was decreased sharply from 35000 to $21728 \mathrm{mg} / \mathrm{L}$ after $1 \mathrm{hr}$ and then decreased gradually to $9682 \mathrm{mg} / \mathrm{L}$ at 6 hrs. This can be attributed to the high osmotic driving force in the beginning 
TABLE 1: Analysis of Ezz Steel treated wastewater and synthetic SW before and after 1st stage of FO-batch process.

\begin{tabular}{|c|c|c|c|c|c|c|c|c|c|c|}
\hline $\begin{array}{l}\text { Time } \\
\text { (hrs) }\end{array}$ & $\begin{array}{c}\mathrm{FS} \\
\mathrm{Fe} \\
(\mathrm{mg} / \mathrm{L})\end{array}$ & $\begin{array}{c}\mathrm{FS} \\
\mathrm{Zn} \\
(\mathrm{mg} / \mathrm{L}) \\
\end{array}$ & $\begin{array}{c}\mathrm{FS} \\
\mathrm{PO}_{4} \\
(\mathrm{mg} / \mathrm{L}) \\
\end{array}$ & $\begin{array}{c}\text { FS } \\
\text { COD } \\
(\mathrm{mg} / \mathrm{L})\end{array}$ & $\begin{array}{c}\text { FS } \\
\text { TDS } \\
(\mathrm{mg} / \mathrm{L}) \\
\end{array}$ & $\begin{array}{c}\text { DS } \\
\text { Fe } \\
(\mathrm{mg} / \mathrm{L}) \\
\end{array}$ & $\begin{array}{c}\mathrm{DS} \\
\mathrm{Zn} \\
(\mathrm{mg} / \mathrm{L})\end{array}$ & $\begin{array}{c}\mathrm{DS} \\
\mathrm{PO}_{4} \\
(\mathrm{mg} / \mathrm{L}) \\
\end{array}$ & $\begin{array}{c}\text { DS } \\
\text { COD } \\
(\mathrm{mg} / \mathrm{L})\end{array}$ & $\begin{array}{c}\text { DS } \\
\text { TDS } \\
(\mathrm{mg} / \mathrm{L}) \\
\end{array}$ \\
\hline 0 & 0.73 & 0.25 & 0.33 & 50 & 1050 & 0 & 0 & 0 & 0 & 35000 \\
\hline 6 & 0.18 & 0.79 & 0.10 & 29 & 3703 & 0 & 0 & 0 & 0 & 9862 \\
\hline
\end{tabular}

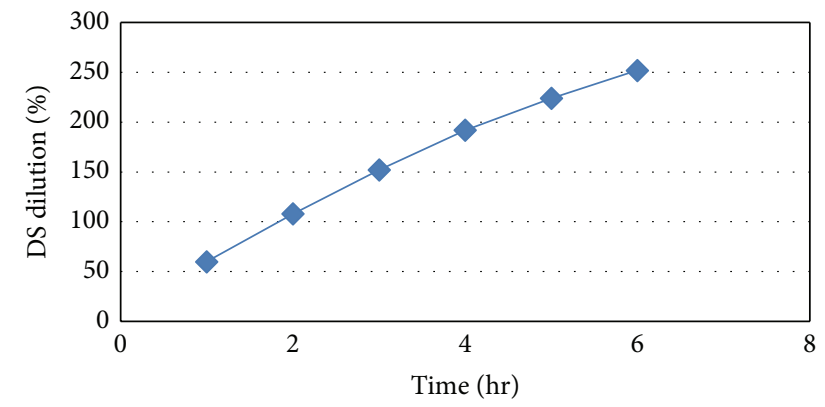

FIGURE 6: DS dilution\% as a function time (1st stage of FO-batch process).

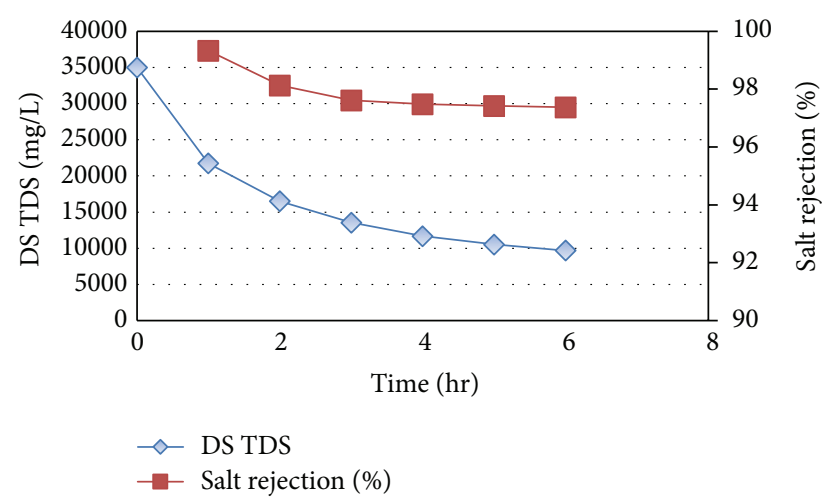

FIGURE 7: DS salinity and salt rejection\% as a function of time (1st stage of FO-batch process).

of the operation which leads to high water flux and fast DS dilution. With respect to salt rejection, it was found that it declined from about $99 \%$ to $98 \%$ after 2 hrs then it remained almost constant around $97.5 \%$.

Table 1 illustrates the analysis of the treated Ezz Steel wastewater and synthetic seawater before and after FO process. The TDS and zinc contents of FS were increased from 1050 and 0.25 to 3703 and $0.79 \mathrm{mg} / \mathrm{L}$, respectively, while COD, iron, and phosphate ions were decreased from 50, 0.73, and 0.33 to $29,0.18$, and $0.1 \mathrm{mg} / \mathrm{L}$, respectively. No COD, iron, zinc, or phosphate ions were observed in DS after the FO process. The decrease of COD, iron, and phosphate in FS may be attributed to the adsorption on the membrane surface, while increasing of zinc ions concentration in FS indicated that it had no adhesive on the membrane surface and the concentration was increased due to the water permeability from FS to DS. The results here gave the same removal behavior of ions in bench scale experiments in which the membrane could retain the ions of $\mathrm{Fe}, \mathrm{PO}_{4}$, and zinc completely.

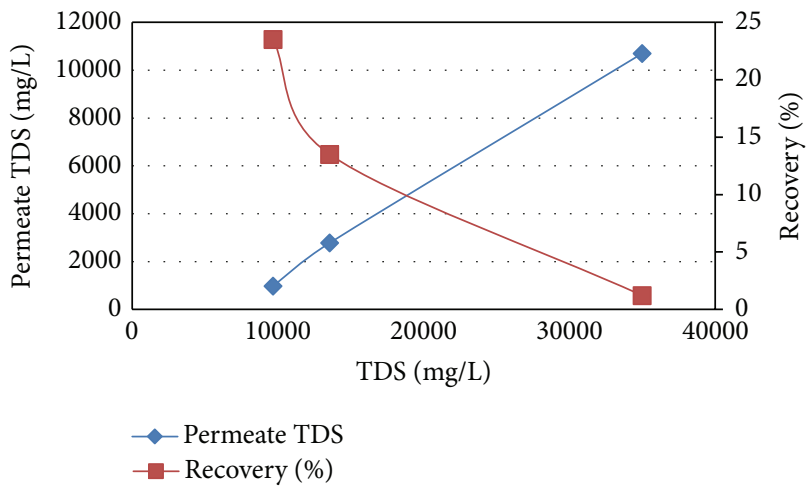

FIGURE 8: Effect of salinity on water recovery and permeate TDS for RO process at 15 bar with synthetic SW and diluted DS from FO process by Ezz Steel treated wastewater.

These results are in good agreement with the literature. Linares et al. [16] illustrated that the rejection of hydrophilic neutral compounds (like iron in our study) was increased with the presence of cake layer on the membrane surface. This can be explained by the high hydrophilicity of the compound, being adsorbed by the cake layer (mainly hydrophilic) and thus preventing the compound from partitioning through the membrane into the DS, forming a double-barrier like system. In addition, Cath et al. [17] demonstrated that phosphate was highly rejected by FO membranes ( $>99.5$ percent).

Gajda and Bogacki [18] proved that the easiest ions to extract by membranes from the solutions are zinc(II) ions, while Park et al. [19] illustrated that the reactivity of zinc ions with carbonyl group is weak. These demonstrated the high rejection value of zinc ions and explained increasing of zinc ions in FS due to the weak anion reactivity of zinc with carbonyl group on the CTA FO membrane which prevents the adhesion of zinc on the membrane surface.

3.1.2. RO Performance. The performance of low pressure RO with diluted DS from first stage of FO was tested. The diluted DS from FO process after 3 and 6 hrs operations were used as feed water for RO process.

Figure 8 shows the salinity effect on permeate TDS and water recovery for $\mathrm{RO}$ at pressure of 15 bar. It was obvious that the RO performance was dramatically decreased by increasing water salinity. With synthetic SW at $35000 \mathrm{mg} / \mathrm{L}$ TDS, the permeate TDS was $10700 \mathrm{mg} / \mathrm{L}$ and water recovery was only $1.2 \%$. With diluted DS at $13557 \mathrm{mg} / \mathrm{L}$ TDS ( 3 hrs FO operation), the permeate TDS was decreased to $2780 \mathrm{mg} / \mathrm{L}$ and water recovery increased to $13.5 \%$. Finally, at salinity 
TABLE 2: Source water quality and pressure requirements.

\begin{tabular}{lcr}
\hline Source & Associated salinity (mg/L) & Typical pressure range, psi (bar) \\
\hline Surface (fresh) water (MF/UF) & $<500$ & $15-30(1-2)$ \\
Brackish water (RO) & $500-3500$ & $50-150(3.4-10.3)$ \\
Brackish to saline water (RO/SWRO) & $3500-18,000$ & $150-650(10.3-44.8)$ \\
Seawater, typical range & & $650-1200(44.8-82.7)$ \\
$\quad$ (i) USA & $18,000-36,000$ & \\
(ii) Middle East & $18,000-45,000$ & \\
\hline
\end{tabular}

of $9682 \mathrm{mg} / \mathrm{L}$ (DS after $6 \mathrm{hrs}$ FO operation), permeate TDS decreased to $980 \mathrm{mg} / \mathrm{L}$ and water recovery increased to $23.5 \%$.

It is well known that feed water salinity has the most significant impact on power consumption. Compared to brackish water or other alternative surface water supplies, seawater contains a greater quantity of dissolved salts. The desalination process must overcome osmotic pressure to reverse the flow, forcing water from the "salty" feed side of a membrane to flow to permeate side of the membrane. Table 2 contains the range of typical pressures associated with feed water salinity. As such, it is clear to see that as feed water salinity increases, the required membrane feed pressure (and associated energy) is increased until the practical limitation of 82.7 bar for drinking water production is reached. At this point the actual feed water recovery is typically decreased to stay within design pressure limitations [20].

In this study, we conducted the RO experiments by the available low pressure RO pilot unit in our lab, just for comparison and not for investigation of the actual operating parameters needed for industrial implantation.

3.1.3. 2nd Stage of FO Process. In the second stage of FO process the concentrated FS from first stage of FO was used as FS, while the concentrated water from RO process was used as DS. This is done to extract additional water from the Ezz Steel wastewater stream, reducing its volume. Consequently, the concentrated Ezz Steel wastewater stream could be returned to a wastewater treatment plant for retreatment or used for beneficial purposes. In doing so, the RO concentrate is diluted, thus reducing the environmental impacts associated with discharging RO brine back to the sea.

Figure 9 illustrates the water and reverse salt fluxes versus FO permeation time for second stage of $\mathrm{FO}$ process with using concentrated FS from first FO stage after $6 \mathrm{hrs}$ as FS and $\mathrm{RO}$ brine as DS. The trend was found to be the same as in the first stage but with lower values. The maximum water flux was $6.25 \mathrm{~L} / \mathrm{m}^{2} \mathrm{hr}$ at $1 \mathrm{hr}$ and it declined to 3.65 after $3 \mathrm{hrs}$, while in the first stage it reached $8.44 \mathrm{~L} / \mathrm{m}^{2} \mathrm{hr}$ at $1 \mathrm{hr}$ and it declined to 6.61 after $6 \mathrm{hrs}$. This is due to low osmotic driving force in second stage of FO process. Figure 10 represents the \% DS dilution as a function of time, while Figure 11 shows DS, TDS, and salt rejection versus FO permeation time. The maximum dilution $\%$ after $3 \mathrm{hrs}$ was $70 \%$ which resulted in decrease of DS and TDS from 13800 to $7990 \mathrm{mg} / \mathrm{L}$, respectively, while the salt rejection was decreased gradually from $99.5 \%$ at $1 \mathrm{hr}$ to 98.4\% after 3 hrs. Generally, the performance of second FO

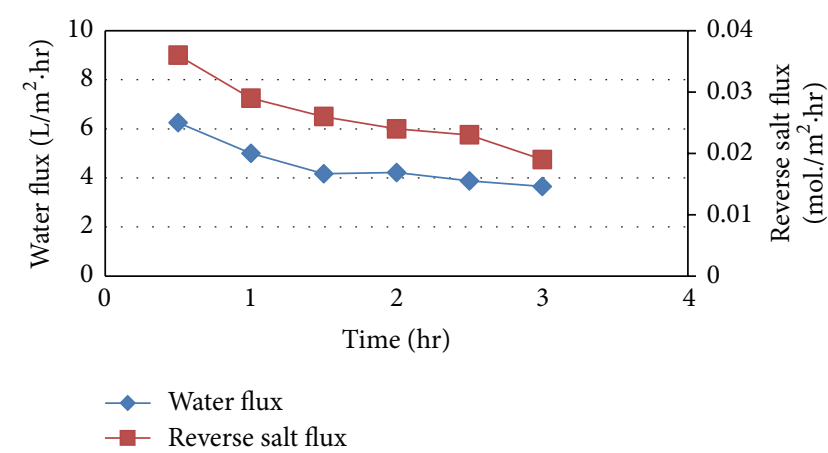

Figure 9: Water and reverse solute fluxes as a function of time (concentrated Ezz Steel treated wastewater from FO after $6 \mathrm{hr}+\mathrm{RO}$ concentrate) (2nd stage of FO-batch process).

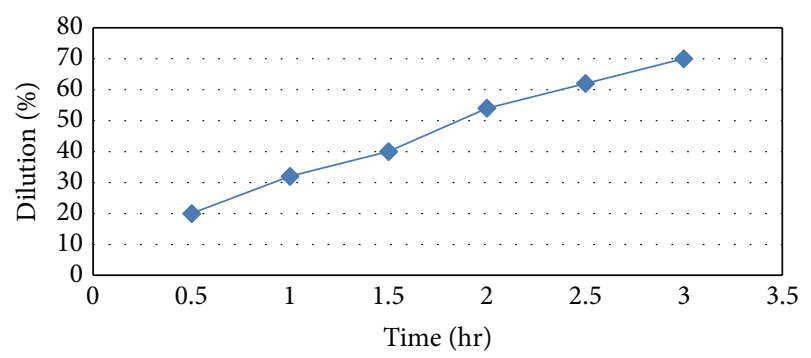

FIGURE 10: Dilution\% as a function time (concentrated Ezz Steel treated wastewater from FO after $6 \mathrm{hr}+\mathrm{RO}$ concentrate) (2nd stage FO-batch process).

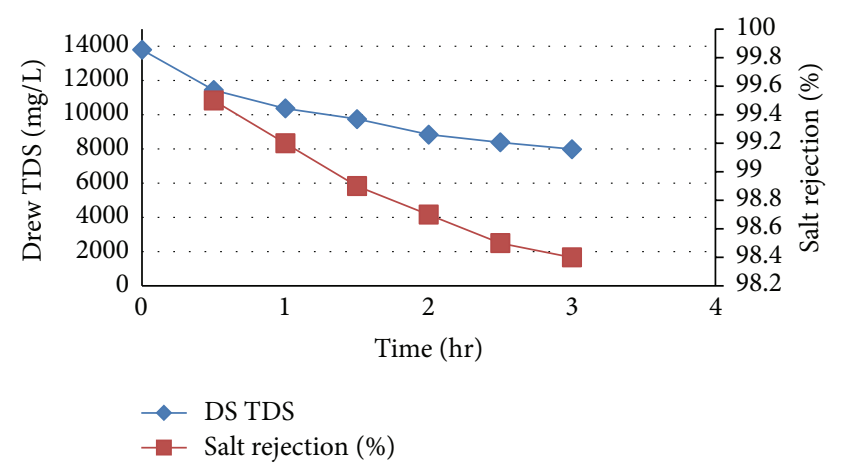

FIGURE 11: DS salinity and salt rejection\% as a function of time (concentrated Ezz Steel treated wastewater from FO after $6 \mathrm{hr}+\mathrm{RO}$ concentrate) (2nd stage of FO-batch process). 
TABLE 3: Analysis of concentrated Ezz Steel treated wastewater from FO after 6 hrs and RO concentrate before and after 2nd stage of FO-batch process.

\begin{tabular}{|c|c|c|c|c|c|c|c|c|c|c|}
\hline $\begin{array}{l}\text { Time } \\
\text { (hrs) }\end{array}$ & $\begin{array}{c}\mathrm{FS} \\
\mathrm{Fe} \\
(\mathrm{mg} / \mathrm{L})\end{array}$ & $\begin{array}{c}\mathrm{FS} \\
\mathrm{Zn} \\
(\mathrm{mg} / \mathrm{L}) \\
\end{array}$ & $\begin{array}{c}\mathrm{FS} \\
\mathrm{PO}_{4} \\
(\mathrm{mg} / \mathrm{L}) \\
\end{array}$ & $\begin{array}{c}\mathrm{FS} \\
\mathrm{COD} \\
(\mathrm{mg} / \mathrm{L})\end{array}$ & $\begin{array}{c}\text { FS } \\
\text { TDS } \\
(\mathrm{mg} / \mathrm{L}) \\
\end{array}$ & $\begin{array}{c}\mathrm{DS} \\
\mathrm{Fe} \\
(\mathrm{mg} / \mathrm{L}) \\
\end{array}$ & $\begin{array}{c}\mathrm{DS} \\
\mathrm{Zn} \\
(\mathrm{mg} / \mathrm{L})\end{array}$ & $\begin{array}{c}\mathrm{DS} \\
\mathrm{PO}_{4} \\
(\mathrm{mg} / \mathrm{L}) \\
\end{array}$ & $\begin{array}{c}\text { DS } \\
\text { COD } \\
(\mathrm{mg} / \mathrm{L}) \\
\end{array}$ & $\begin{array}{c}\text { DS } \\
\text { TDS } \\
(\mathrm{mg} / \mathrm{L}) \\
\end{array}$ \\
\hline 0 & 0.18 & 0.79 & 0.10 & 29 & 3703 & 0 & 0 & 0 & 0 & 13800 \\
\hline 3 & 0.1 & 1.6 & 0.04 & 17 & 7960 & 0 & 0 & 0 & 0 & 7990 \\
\hline
\end{tabular}

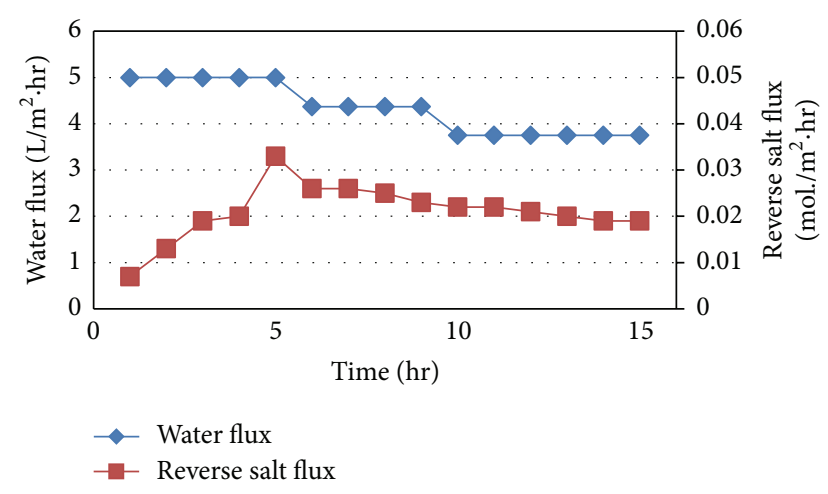

FIGURE 12: FO water and reverse solute fluxes as a function of time for $\mathrm{FO} / \mathrm{RO}$ continuous experiment.

stage was markedly low; the decision of its industrial implementation was dependent on technoeconomic evaluation of the complete process.

Table 3 illustrates the analysis of the concentrated Ezz Steel treated wastewater and RO concentrate before and after second stage of FO process. As in the first FO stage, the TDS and zinc contents of FS were increased from 3703 and 0.79 to 7960 and $1.6 \mathrm{mg} / \mathrm{L}$, respectively, while COD, iron, and phosphate ions were decreased from $29,0.18$, and 0.1 to $17,0.1$, and $0.04 \mathrm{mg} / \mathrm{L}$, respectively. No COD, iron, zinc, or phosphate ions were observed in DS after the FO process.

3.2. Continuous Experiments Results. Based on the results of FO-batch experiment the salinity of SW was decreased from 35000 to $9682 \mathrm{mg} / \mathrm{L}$ after $6 \mathrm{hrs}$ permeation time. So, we started the continuous FO/RO experiment after 6 hrs of FO operation for decreasing the TDS of SW to be suitable with the available low pressure RO in the lab.

Figure 12 demonstrates the effect of FO permeation time on FO water flux and reverse salt flux. It is found that the water flux takes three constant regimes with time: from the beginning of operation till $5 \mathrm{hrs}$ it was $5 \mathrm{~L} / \mathrm{m}^{2} \mathrm{hr}$, then from 5 to $9 \mathrm{hrs}$ it became 4.37 , and from 9 to end of operation at $15 \mathrm{hrs}$ it was $3.75 \mathrm{~L} / \mathrm{m}^{2} \mathrm{hr}$. The gradual decrease in water flux may be attributed to fouling caused by the presence of mixture of elements $\left(\mathrm{Fe}, \mathrm{Zn}\right.$, and $\left.\mathrm{PO}_{4}\right)$ and reduction of osmotic driving force by dilution of DS.

$\mathrm{Mi}$ and Elimelech [21] observed a strong correlation between intermolecular adhesion and fouling in FO. They indicated that strong foulant-foulant interactions, such as adhesion, caused faster accumulation of foulant on the membrane surface. This finding is in good agreement with the above results, where ion mixture interactions and iron concentration caused accumulation of foulant on the membrane surface leading to water flux lowering. However, the behavior of reverse salt flux with time was affected by the reduction of water flux, in which it increased from 0.007 to $0.033 \mathrm{~mol} . / \mathrm{m}^{2} \mathrm{hr}$ through the first five hours due to the high water flux in this period; by increasing FO permeation time it was slightly decreased to $0.019 \mathrm{~mol} . / \mathrm{m}^{2} \mathrm{hr}$ at $15 \mathrm{hrs}$ due to the decreasing of water flux.

Moreover, Chun et al. [22] investigated water flux and fouling behaviors of the FO process during $48 \mathrm{hrs}$ of continuous operation. The results indicated that the flux was nearly constant during the first $17 \mathrm{hrs}$, while only $13 \%$ decline occurred by the end of operation. They explained that FO mode offers less fouling/scaling as the dense and smooth active layer prevents the fouling/scaling. The shear stress on the smooth surface of FO mode inhibits the accumulation of the foulants on the active layer and reduced ECP (external concentration polarization) on both sides of the surface. This may explains the presence of three constant regimes of flux decline with time in our study, in which the accumulation of fouling layer may take time interval.

In addition, the authors previously investigated the performance of the combined $\mathrm{FO} / \mathrm{RO}$ desalination hybrid system to cotreat brackish water and agriculture Canal water [23]. The results indicated that the water flux remained constant during $15 \mathrm{hrs}$ of continuous operation, this contributes to the fact that the Canal water used in this study did not contain heavy metals, and organic pollutants are the major contaminant present in it. According to Mi and Elimelech [21] they demonstrated that the more loose and sparse organic fouling layer in FO membrane is weaker and easier to break than inorganic fouling layer.

Figure 13 shows the changes of RO permeate TDS and flux with time; it is clear that the TDS was decreased gradually with time, while the flux was increased; this is due to the dilution of DS by time.

Table 4 illustrates the analysis of the Ezz Steel treated wastewater and diluted synthetic SW before and after FO/RO continuous experiment. As observed in batch experiments, no COD, iron, zinc, or phosphate ions were observed in DS after the FO process. With respect to FS, the zinc content of FS remained almost constant at $0.25 \mathrm{mg} / \mathrm{L}$, while COD, iron, and phosphate ions decreased from $50,0.73$, and 0.33 to 12 , 0.09 , and $0.05 \mathrm{mg} / \mathrm{L}$, respectively.

The increasing of RO permeates flux by time due to DS dilution indicated that no fouling occurs on RO membrane surface which can be explained by the absence of pollutants in DS. 
TABLE 4: Analysis of Ezz Steel treated wastewater and diluted synthetic SW before and after FO/RO continuous process.

\begin{tabular}{|c|c|c|c|c|c|c|c|c|}
\hline $\begin{array}{l}\text { Time } \\
\text { (hrs) }\end{array}$ & $\begin{array}{c}\mathrm{FS} \\
\mathrm{Fe} \\
(\mathrm{mg} / \mathrm{L})\end{array}$ & $\begin{array}{c}\mathrm{FS} \\
\mathrm{Zn} \\
(\mathrm{mg} / \mathrm{L})\end{array}$ & $\begin{array}{c}\mathrm{FS} \\
\mathrm{PO}_{4} \\
(\mathrm{mg} / \mathrm{L})\end{array}$ & $\begin{array}{c}\text { FS } \\
\text { COD } \\
(\mathrm{mg} / \mathrm{L}) \\
\end{array}$ & $\begin{array}{c}\mathrm{DS} \\
\mathrm{Fe} \\
(\mathrm{mg} / \mathrm{L})\end{array}$ & $\begin{array}{c}\mathrm{DS} \\
\mathrm{Zn} \\
(\mathrm{mg} / \mathrm{L})\end{array}$ & $\begin{array}{c}\mathrm{DS} \\
\mathrm{PO}_{4} \\
(\mathrm{mg} / \mathrm{L}) \\
\end{array}$ & $\begin{array}{c}\text { DS } \\
\text { COD } \\
(\mathrm{mg} / \mathrm{L}) \\
\end{array}$ \\
\hline 0 & 0.73 & 0.25 & 0.33 & 50 & 0 & 0 & 0 & 0 \\
\hline 15 & 0.09 & 0.24 & 0.05 & 12 & 0 & 0 & 0 & 0 \\
\hline
\end{tabular}

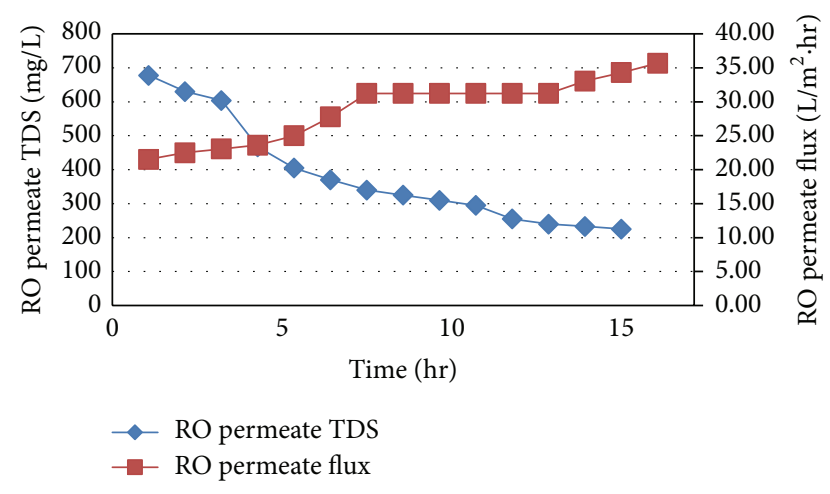

FIGURE 13: RO permeate TDS and flux as a function of time for FO/ $\mathrm{RO}$ continuous experiment.

\section{Conclusion and Recommendations}

Finally, we can conclude that the overall performance of pilot $\mathrm{FO} / \mathrm{RO}$ process is higher than that obtained in bench scale experiments and the FO membrane can prevent all pollutants in FS from migration to DS. The dilution rate of SW reached $250 \%$ using FO system which leads to the reduction of SW salinity from 35000 to $10000 \mathrm{mg} / \mathrm{L}$ after $6 \mathrm{hrs}$. The FO/RO system was tested on continuous operation for $15 \mathrm{hrs}$, and there were no pollutants detected neither in DS nor in RO permeate after the end of operating time. In addition, water flux in FO process was found to decrease slightly by time due to the fouling caused by presence of mixture of ions in the wastewater.

\section{Competing Interests}

The authors declare that they have no competing interests.

\section{Acknowledgments}

This work was conducted in National Research Center and funded by Science and Technology Development Fund in Egypt (STDF). The authors appreciate Ezz Steel Company for production of high-quality long and flat steel in Alexandria and for their kind support through the supply of real industrial wastewater used in this study.

\section{References}

[1] J. L. Prante, J. A. Ruskowitz, A. E. Childress, and A. Achilli, "ROPRO desalination: an integrated low-energy approach to seawater desalination," Applied Energy, vol. 120, pp. 104-114, 2014.
[2] S. Phuntsho, S. Sahebi, T. Majeed, F. Lotfi, J. E. Kim, and H. K. Shon, "Assessing the major factors affecting the performances of forward osmosis and its implications on the desalination process," Chemical Engineering Journal, vol. 231, pp. 484-496, 2013.

[3] A. Altaee, G. Zaragoza, and H. R. van Tonningen, "Comparison between Forward Osmosis-Reverse Osmosis and Reverse Osmosis processes for seawater desalination," Desalination, vol. 336, no. 1, pp. 50-57, 2014.

[4] D. Y. Kim, B. Gu, J. Ha Kim, and D. Ryook Yang, "Theoretical analysis of a seawater desalination process integrating forward osmosis, crystallization, and reverse osmosis," Journal of Membrane Science, vol. 444, pp. 440-448, 2013.

[5] S. Phuntsho, S. Hong, M. Elimelech, and H. K. Shon, "Forward osmosis desalination of brackish groundwater: meeting water quality requirements for fertigation by integrating nanofiltration," Journal of Membrane Science, vol. 436, pp. 1-15, 2013.

[6] A. Altaee, A. Mabrouk, and K. Bourouni, "A novel forward osmosis membrane pretreatment of seawater for thermal desalination processes," Desalination, vol. 326, pp. 19-29, 2013.

[7] M. Xie, L. D. Nghiem, W. E. Price, and M. Elimelech, "Relating rejection of trace organic contaminants to membrane properties in forward osmosis: measurements, modelling and implications," Water Research, vol. 49, pp. 265-274, 2014.

[8] F.-X. Kong, H.-W. Yang, X.-M. Wang, and Y. F. Xie, "Rejection of nine haloacetic acids and coupled reverse draw solute permeation in forward osmosis," Desalination, vol. 341, no. 1, pp. $1-9,2014$.

[9] K. Lutchmiah, A. R. D. Verliefde, K. Roest, L. C. Rietveld, and E. R. Cornelissen, "Forward osmosis for application in wastewater treatment: a review," Water Research, vol. 58, pp. 179-197, 2014.

[10] H. D. Raval and P. Koradiya, "Direct fertigation with brackish water by a forward osmosis system converting domestic reverse osmosis module into forward osmosis membrane element," Desalination and Water Treatment, vol. 336, pp. 1-8, 2015.

[11] A. Bennett, "Desalination and water reuse: what's the future for forward osmosis?” Desalination Report, Filtration + Separation, 2013.

[12] Y. Cha, "Korea's Smart Water Grid and hybrid desalination technology," 2014, http://www.rvo.nl/onderwerpen/innovatiefondernemen/topsectoren/ia-netwerk.

[13] H. Gadallah, H. M. Ali, S. S. Ali, R. Sabry, and A. Gadallah, "Application of forward/reverse osmosis hybrid system for seawater desalination using impaired water from steel industry, part (1): FO performance," European Journal of Scientific Research, vol. 126, no. 2, 2014.

[14] S. Zhao, L. Zou, and D. Mulcahy, "Brackish water desalination by a hybrid forward osmosis-nanofiltration system using divalent draw solute," Desalination, vol. 284, pp. 175-181, 2012.

[15] G. Blandin, A. R. D. Verliefde, C. Y. Tang, A. E. Childress, and P. Le-Clech, "Validation of assisted forward osmosis (AFO) process: impact of hydraulic pressure," Journal of Membrane Science, vol. 447, pp. 1-11, 2013. 
[16] R. V. Linares, V. Yangali-Quintanilla, Z. Li, and G. Amy, "Rejection of micropollutants by clean and fouled forward osmosis membrane," Water Research, vol. 45, no. 20, pp. 6737-6744, 2011.

[17] T. Y. Cath, J. E. Drewes, C. D. Lundin, and N. T. Hancock, "Forward osmosis-reverse osmosis process offers a novel hybrid solution for water purification and reuse," IDA Journal of Desalination and Water Reuse, vol. 2, no. 4, pp. 16-20, 2010.

[18] B. Gajda and M. B. Bogacki, "The application of polymer inclusive membranes for removal of heavy metal ions from waste solutions," Journal of Achievements in Materials and Manufacturing Engineering, vol. 55, no. 2, pp. 673-678, 2012.

[19] J. S. Park, S. K. Kim, and K. H. Lee, "Effect of $\mathrm{ZnCl}_{2}$ on formation of asymmetric PEI membrane by phase inversion process," Journal of Industrial and Engineering Chemistry, vol. 6, no. 2, pp. 93-99, 2000.

[20] White Paper, Water Reuse Association Desalination Committee, Seawater Desalination Power Consumption, November 2011.

[21] B. Mi and M. Elimelech, "Chemical and physical aspects of organic fouling of forward osmosis membranes," Journal of Membrane Science, vol. 320, no. 1-2, pp. 292-302, 2008.

[22] Y. Chun, S.-J. Kim, G. J. Millar, D. Mulcahy, I. S. Kim, and L. Zou, "Forward osmosis as a pre-treatment for treating coal seam gas associated water: flux and fouling behaviours," Desalination, 2015.

[23] R. Sabry, A. G. Gadallah, S. S. Ali, H. M. Ali, and H. Gadallah, "Application of forward/reverse osmosis hybrid system for brackish water desalination using El-Salam canal water, Sinai, Egypt, part (2): pilot scale investigation ", International Journal of ChemTech Research, vol. 8, no. 11, pp. 102-112, 2015. 


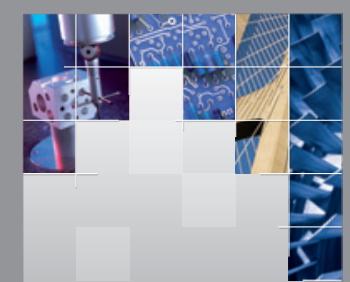

\section{Enfincering}
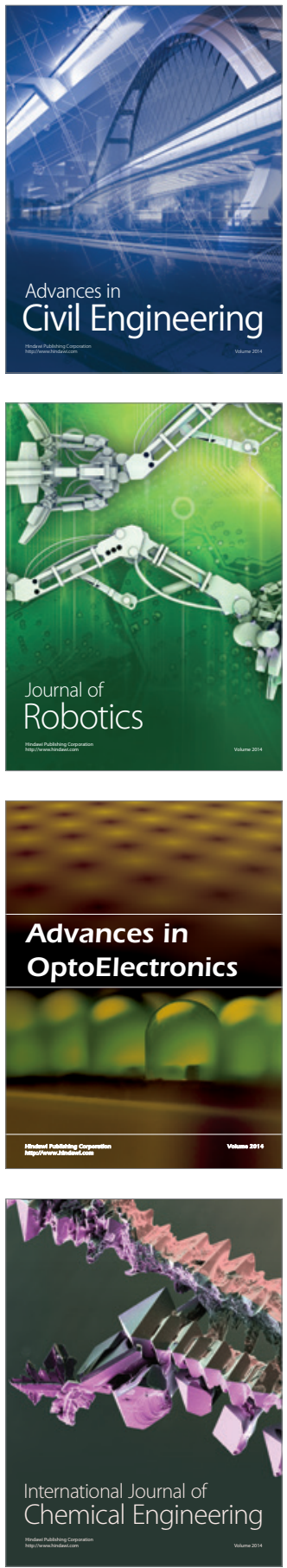

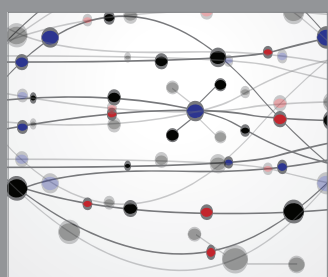

The Scientific World Journal

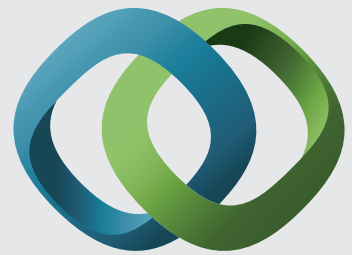

\section{Hindawi}

Submit your manuscripts at

http://www.hindawi.com
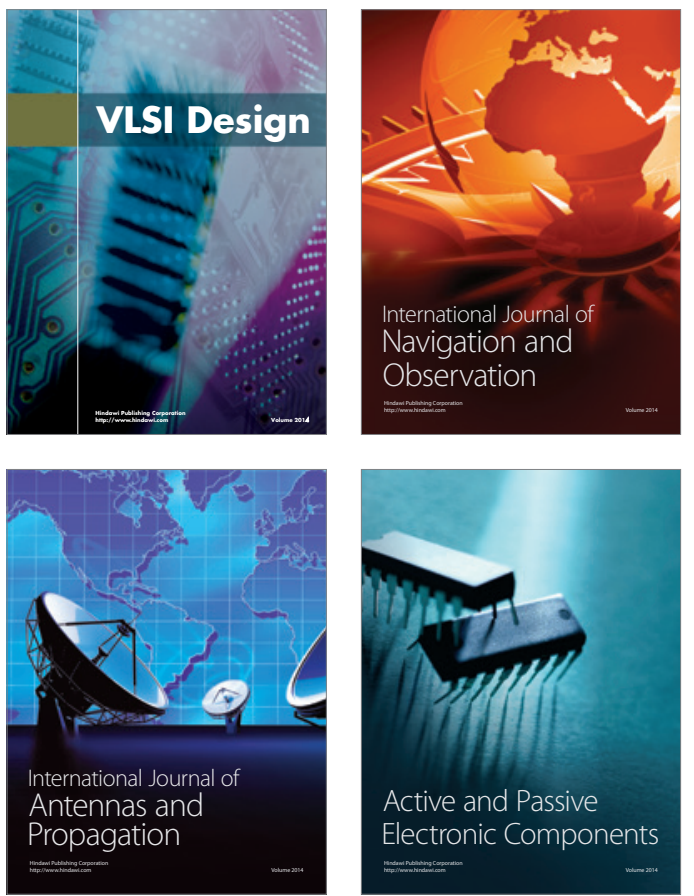
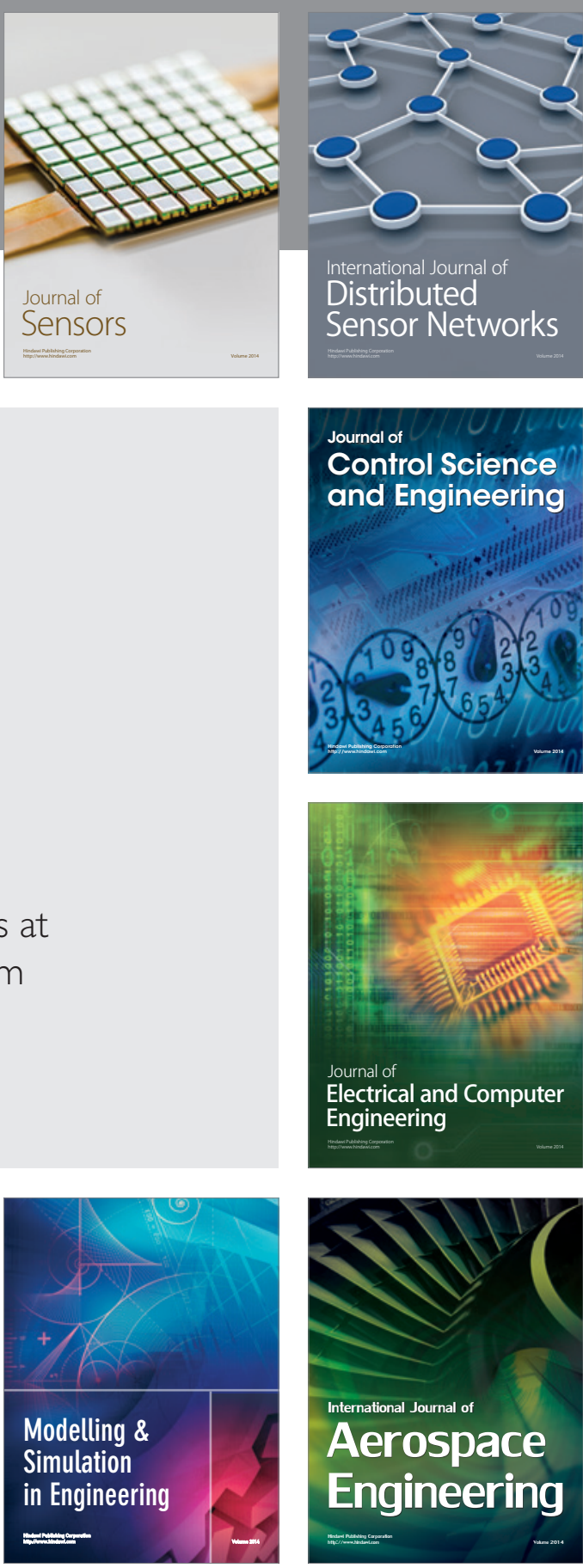

International Journal of

Distributed

Sensor Networks

Journal of

Control Science

and Engineering
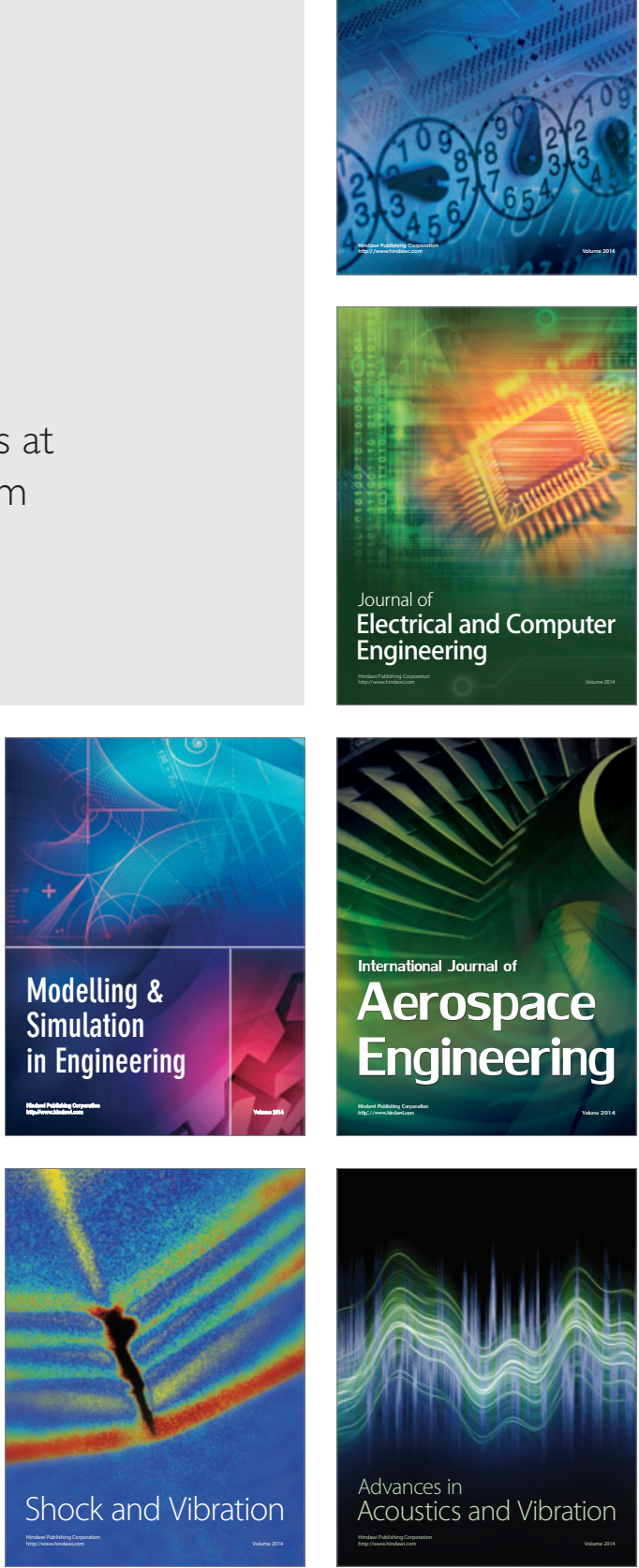